\title{
ANALYSIS OF POWER QUALITY IMPROVEMENT IN GRID CONNECTED WIND DRIVEN INDUCTION GENERATOR AT VARIOUS LOAD CONDITIONS
}

\author{
Sk. Baji babu ${ }^{1}$, M. Balasubba Reddy ${ }^{2}$, T.Madhu ${ }^{3}$ \\ ${ }^{1}$ M. Tech Scholar (P.E), ${ }^{2}$ Professor \& H.O.D, ${ }^{3}$ Assistant Professor, Department of EEE, Prakasam Engineering College, \\ Kandukur, Andhra Pradesh, India, \\ bajibabu207@gmail.com,balasubbareddy@yahoo.com,tallapanenimadhu@gmail.com
}

\begin{abstract}
As a promising renewable alternative, the wind power is one of the significant sources of generation. Reactive power compensation and harmonic reduction in a low voltage distribution networks for integration of wind power to the grid are the main issues addressed in this paper. This paper proposes a control scheme based on instaneous $P q$ theory for compensating the reactive power requirement of a three phase grid connected wind driven induction generator as well as the harmonics produced by the non linear load connected to the PCC using STATCOM. The proposed control scheme is simulated using MATLAB/SIMULINK. The Simulation results are presented in this paper.
\end{abstract}

Keywords- wind power, distribution network, induction generator, STATCOM, reactive power.

\section{INTRODUCTION}

The integration of wind power to grid introduces power quality issues, which mainly consist of voltage regulation and reactive power compensation Induction machines are mostly used as generators in wind power based generations. Induction generators draw reactive power from the grid to which they are connected. Therefore, the integration of wind power to power system networks is one of the main concerns of the power system engineers. The addition of wind power into the electric grid affect's the power quality [I].During the last few years, power electronic technology plays an important role in distributed generation and integration of in $d$ energy generation into the electric grid[2]. A non-linear load on a power system is typically a rectifier (such as used in a power supply), some kind of arc discharge device such as fluorescent lamp, electric welding machine, or arc furnace because current in these systems is interrupted by a switching action, the current contains frequency components that are multiples of the power system frequency. It changes the shape of the current wave form from a sine wave to some other form and also create harmonic currents in addition to the original(fundamental frequency) AC current. The most used unit to reduce the harmonics produced by the non linear load. Compensate for reactive power in the power systems are either synchronous condensers or shunt capacitors, the latter either with mechanical switches or with thyristor switch, as in Static VAR Compensator (SVC). The disadvantage of using shunt Capacitor is that the reactive power supplied is proportional to the square of the voltage. Consequently, the reactive power supplied from the capacitors decreases rapidly when the voltage decreases [3] .To overcomes the above disadvantages; STATCOM is best suited for reactive power compensation and harmonic reduction. It is based on a controllable voltage source converter (VSC). By control of the voltage source converter output voltage in relation to the grid voltage, the voltage source converter will appear as a generator or absorber of reactive power [6].Fig I show the block diagram of grid connected system. In this 3-phase separately excited induction generator feeding non linear load has been presented. A STATCOM is connected at the point of common coupling with this system in order to compensate the reactive power requirements of induction generator as well as load and also to reduce the harmonics produced by the non linear load.

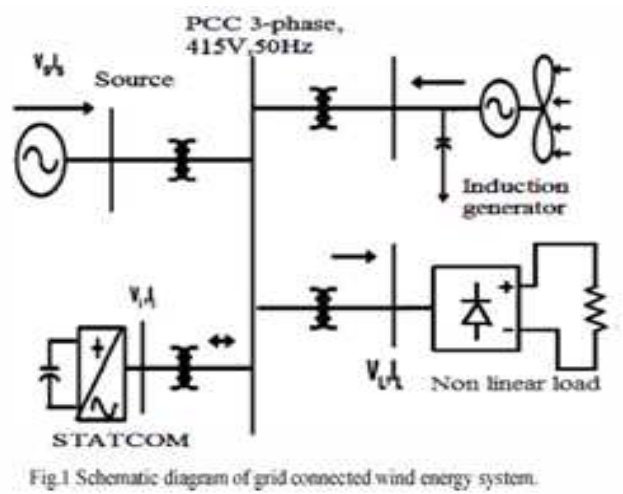


The proposed STATCOM control scheme for grid connected wind energy generation for power quality improvement has following objective.

This paper is organized as follows. Section II discusses reactive power requirements of induction generator. Section III, IV and V discuss wind driven induction generator with STATCOM, reference current generation and hysteresis current controller for STATCOM respectively.

\section{REACTIVE POWER REQUIREMENTS OF INDUCTION GENERATOR}

The induction generators are widely used, due to the advantage of cost effectiveness, robustness, ruggedness, simplicity and requirement of no brush and commutators.

However; induction generators require reactive power for magnetization. When the generated active power of an induction generator is varied due to wind, absorbed reactive power and terminal voltage of an induction generator can be significantly affected.

A Three phase induction generator feeding a non linear load as well as connected to the grid is simulated using MATLAB/Simulink to study the reactive power requirement of IG and also harmonics produced by the non linear load. Simulation diagram of this system is shown in Fig2.

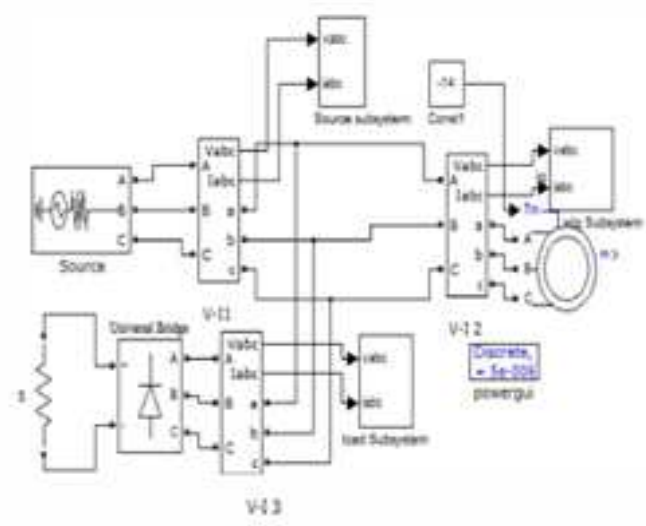

Fig 2.30 separately excited induction gencrator feeding non linear load.

\section{WIND DRIVEN INDUCTION GENARATOR WITH STATCOM}

During the operation induction generator draws reactive power from the grid for its magnetization. Non linear load distorts the grid current waveform and also increase the harmonic component. Due to this, grid current is not in phase with the grid voltage and its wave shape is also different from sine wave which is shown in fig 3 .
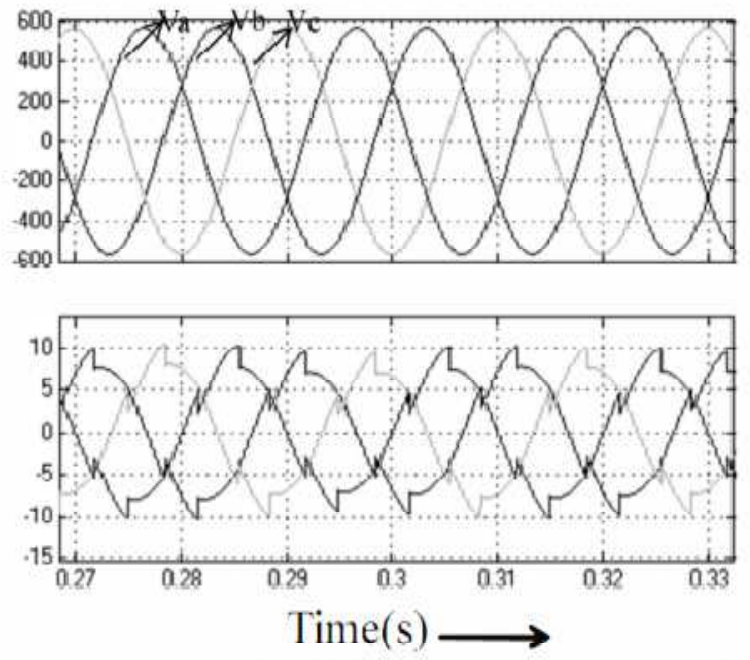

Fig.3 Instantaneous Value of grid voltage and current for Grid connected system with non linear load.

Hence the power factor is not unity. Reactive power requirement of induction generator and load is supplied by the grid. Grid reactive power is the sum of both induction generator and load reactive power is shown in Table I. Grid reactive power, load current and induction generator current is shown in fig 4, 5 and 6 respectively.

Table I

\begin{tabular}{|c|c|c|c|}
\hline Parameters & Grid & $\begin{array}{c}\text { Induction } \\
\text { generaror }\end{array}$ & Lad \\
\hline $\begin{array}{c}\text { Reactive } \\
\text { power(VAR) }\end{array}$ & 3307 & 1930 & 1377 \\
\hline $\begin{array}{c}\text { Active } \\
\text { Power(W) }\end{array}$ & -6283 & -8400 & 2117 \\
\hline
\end{tabular}

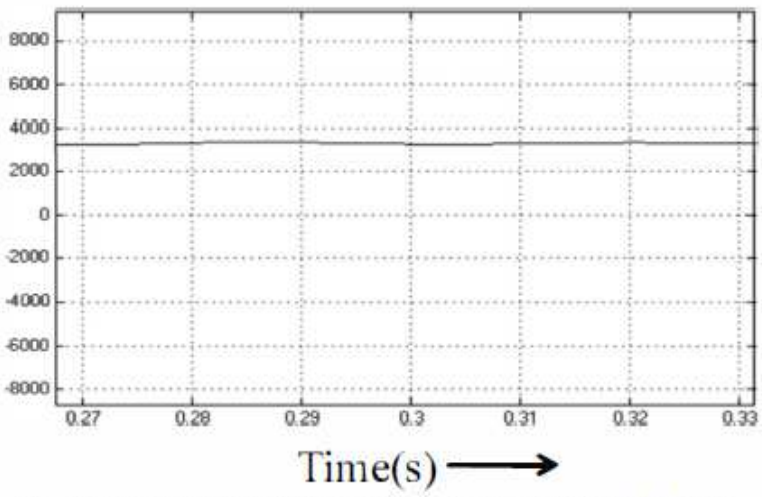

Fig.4 Instantaneous Value of reactive power supplied by grid. 


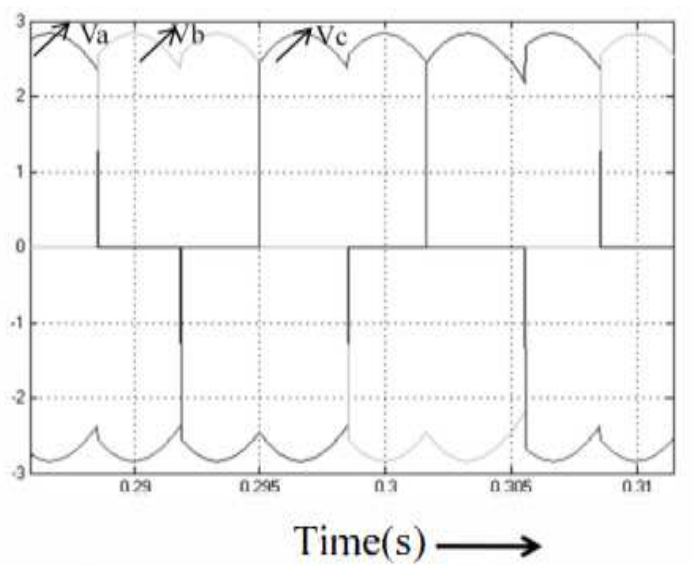

Fig.5 Instantaneous Value of Load current.

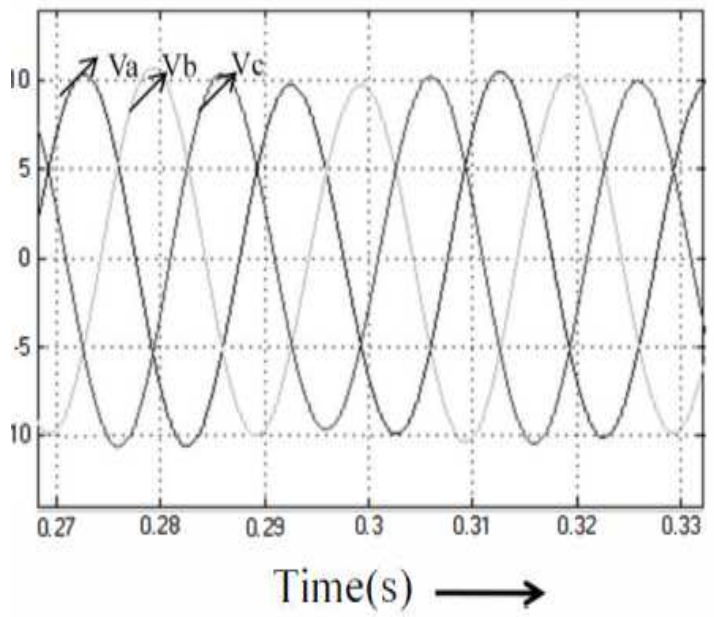

Fig.6 Instantaneous Value of induction generator current.

The shunt connected STATCOM is connected to the PCC through interfacing inductors. The induction generator and load is also connected to the PCC [13]. The STATCOM compensator output is controlled, so as to maintain the power quality norms in the grid system

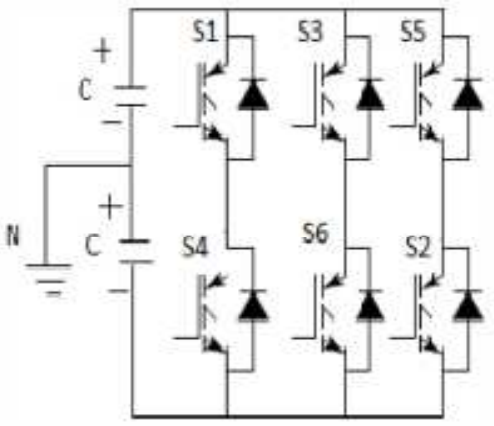

Fig 7.Six Pulse VSI STATCOM
In earlier case reactive power requirement of induction generator and load is supplied by the grid, excess of power feeding the load is fed back to the grid which is shown in Table I. But in the proposed system with STATCOM, reactive power requirement of induction generator and load is supplied by the STATCOM instead of grid. The STATCOM injects a compensating current of variable magnitude and frequency component at the PCC [8]-[10]. Simulation diagram of separately excited induction generator feeding non linear load with STATCOM is shown in fig 8.

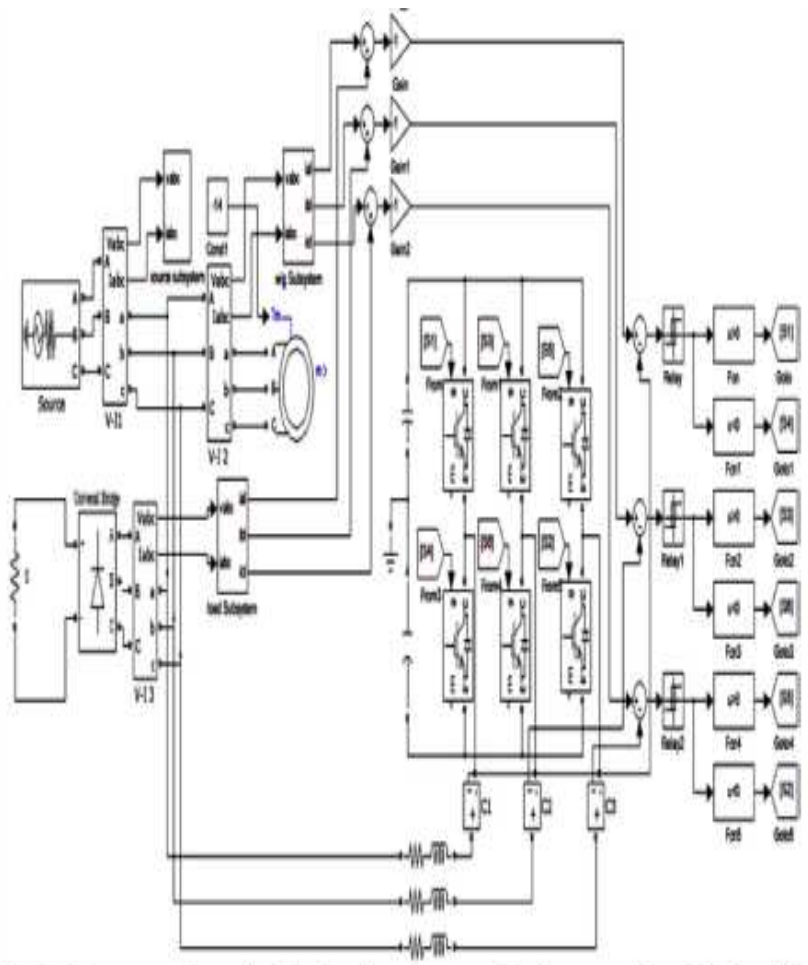

Fig.8. 3\$ separately excited induction generator feeding non linear load with STATCOM.

\section{REFERENCE CURRENTGENERATION FOR STATCOM}

Reference current for the STATCOM is generated based on instantaneous reactive power theory [7]-[1O]. A STATCOM injects the compensation current which is a sum of reactive component current of IG, non-linear load and harmonic component current of non-linear load.

$\mathrm{Pq}$ theory gives a generalized definition of instantaneous reactive power, which is valid for sinusoidal or non sinusoidal, balanced or unbalanced, three-phase power systems with or without zero sequence currents and/or voltages. 


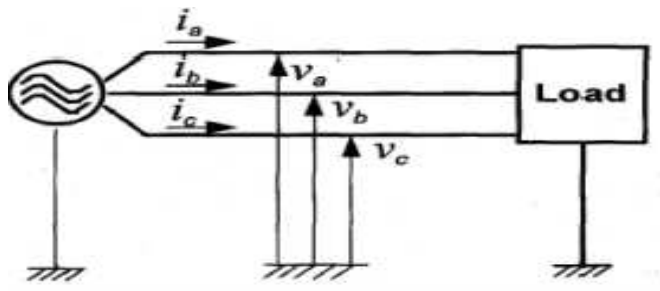

Fig .9 Three phase power system

Fig.9 shows the three phase power system, instantaneous Voltages, va, Vb, vc in volts and instantaneous currents, ia, ib, icin amps of a three phase system are expressed as instantaneous space vectors ' $v$ ' and 'i' given by(l)

$$
v=\left(\begin{array}{l}
v_{a} \\
v_{b} \\
v_{c}
\end{array}\right) \quad i=\left(\begin{array}{c}
i_{a} \\
i_{b} \\
i_{c}
\end{array}\right)
$$

' $\mathrm{p}$ ' is the instantaneous active power of a three-phase circuit in Watts, given by (2)

$$
\mathrm{P}=\text { v.I ----- (2). }
$$

Instantaneous active power of a three-phase circuit ' $p$ ' is the scalar product of instantaneous voltage and current. It is the product of the sum of three phase voltages and current, given by(3) .

$$
\mathrm{P}=\mathrm{va} i \mathrm{a}+\mathrm{vb} \mathrm{ib}+\mathrm{vc} i \mathrm{c}
$$

Instantaneous active power consists of average component and oscillatory component as given by (4).

$$
\mathrm{P}=\mathrm{Pdc}+\mathrm{Pac}
$$

'Pdc' is the average component of instantaneous active power in watts and 'Pac' is the oscillatory component of instantaneous active power in watts. ' $q$ ' is the instantaneous reactive power of a three-phase circuit in VAR, given by(5)

$$
q=\left\|_{v} \times \mathrm{i}\right\|
$$

Instantaneous reactive power of a three-phase circuit ' $q$ ' is the vector product of instantaneous voltage and current, given by (6).

$$
\mathrm{q}=\left(\begin{array}{c}
\mathrm{q}_{\mathrm{a}} \\
\mathrm{q}_{\mathrm{b}} \\
\mathrm{q}_{\mathrm{c}}
\end{array}\right)=\left(\begin{array}{cc}
\mathrm{v}_{\mathrm{b}} & \mathrm{v}_{\mathrm{c}} \\
\mathrm{i}_{\mathrm{b}} & \mathrm{i}_{\mathrm{c}} \\
\mathrm{v}_{\mathrm{c}} & \mathrm{v}_{\mathrm{a}} \\
\mathrm{i}_{\mathrm{c}} & \mathrm{i}_{\mathrm{a}} \\
\mathrm{v}_{\mathrm{a}} & \mathrm{v}_{\mathrm{b}} \\
\mathrm{i}_{\mathrm{a}} & \mathrm{i}_{\mathrm{b}}
\end{array}\right)
$$

Total current is the sum of instantaneous active, reactive and harmonic component of current is given by (7)

$$
\mathrm{i}=\mathrm{i}_{\mathrm{p}}+\mathrm{i}_{\mathrm{q}}+\mathrm{i}_{\mathrm{h}}
$$

Here ip, iq, ih are instantaneous active, reactive and harmonic component of currents respectively.

'ip 'is the instantaneous active component current in amps given by (8)

$$
\mathrm{i}_{\mathrm{p}}=\frac{\mathrm{p}_{\mathrm{dc}, \mathrm{v}}}{\mathrm{v}_{\mathrm{a}}{ }^{2}+\mathrm{v}_{\mathrm{b}}{ }^{2}+\mathrm{v}_{\mathrm{c}}{ }^{2}}
$$

Since it is a non linear load reactive component and harmonic component current are used as a reference current for STATCOM. The reference current for the three phases as given by (9), (10), (11).

$$
\begin{aligned}
& \mathrm{i}_{\mathrm{af}^{*}}=\mathrm{i}_{\mathrm{ap}^{*}}-\mathrm{i}_{\mathrm{as}}=\mathrm{i}_{\mathrm{aq}}+\mathrm{i}_{\mathrm{ah}} \\
& \mathrm{i}_{\mathrm{bf}}=\mathrm{i}_{\mathrm{bp}^{*}}-\mathrm{i}_{\mathrm{bs}^{*}}=\mathrm{i}_{\mathrm{bq}}+\mathrm{i}_{\mathrm{bh}} \\
& \mathrm{i}_{\mathrm{cf}}=\mathrm{i}_{\mathrm{cp}^{*}}-\mathrm{i}_{\mathrm{cs}}=\mathrm{i}_{\mathrm{cq}}+\mathrm{i}_{\mathrm{ch}}
\end{aligned}
$$

\section{HYSTERESIS CONTROLLER FOR STATCOM}

The current control scheme for STATCOM is using a "hysteresis current controller." Using this technique, the controller keeps the STATCOM current between boundaries of hysteresis area and gives correct switching signals for STATCOM operation [11]-[12].

It is a feedback current control method where the actual current tracks the reference current within a hysteresis band. The current controller generates the firing pulses to the VSI by comparing the reference and actual current.

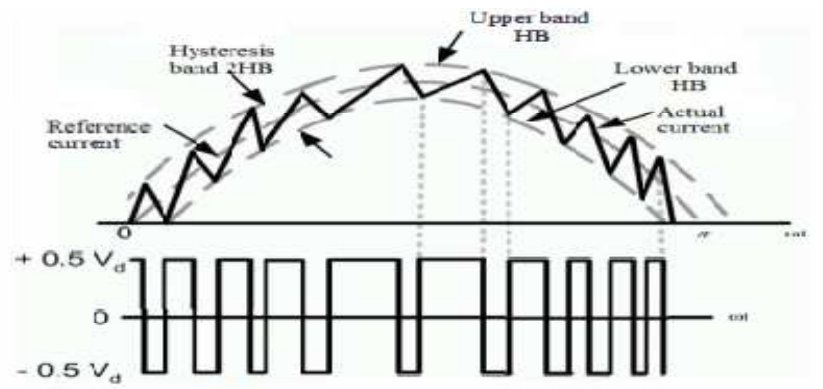

Fig 10.Hysteresis current modulation

The hysteresis current control scheme for generating the switching signals to the STATCOM is shown in Fig.10. If the current exceeds the upper limit of the hysteresis band, upper switch of the inverter arm is turned off and the lower switch is turned on. As a result, the current start to decay. If the current crosses the lower limit of the hysteresis band, the lower switch of the inverter arm is turned off and the upper switch is turned on. 
As a result, the current gets back into the hysteresis band. Hence, the actual current is forced to track the reference current within the hysteresis band. The choice of the current band depends on the value of compensation current and the interfacing inductance.

\section{SIMULATION RESULTS}

The performance of the system is analyzed with and without STATCOM by switching ON the STATCOM at time $\mathrm{t}=0.3 \mathrm{~s}$. The simulation parameters considered are given in Table 1.Initially the STACOM current is zero after 0.3 seconds the STATCOM starts tracking the reference current within the hysteresis band which is shown in Fig 11.Gridcurrent is not in phase with voltage during

STATCOM OFF condition and in ON condition grid current is 1800 out of phase with voltage, which signifies that the excess power after feeding the non linear load is fed back to the source which is shown in fig 12 and 13 respectively.

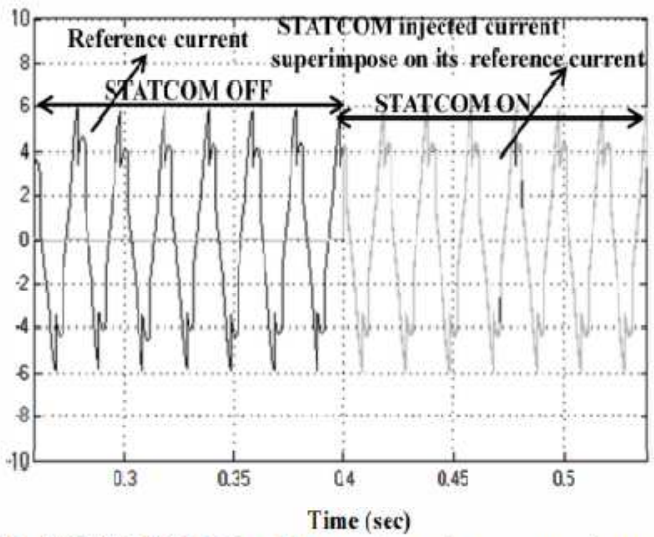

Fig 11.STATCOM injected current superimpose on reference current.
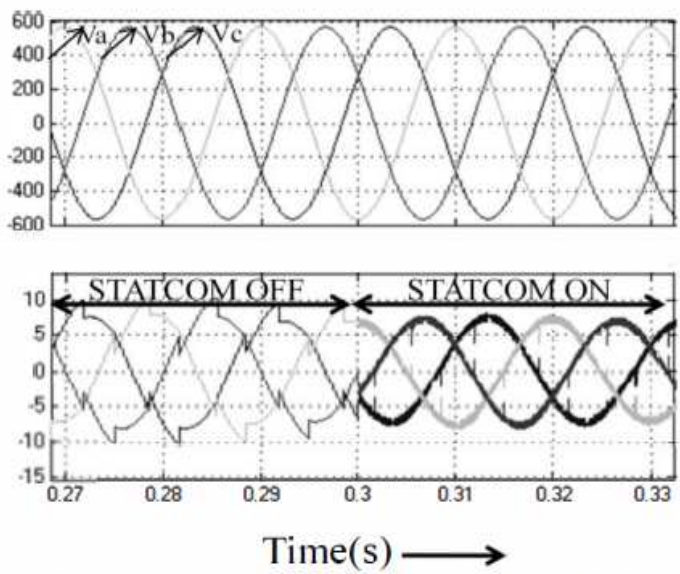

Fig 12. Instantaneous Value of grid voltage and current for Grid connected system with non linear load.

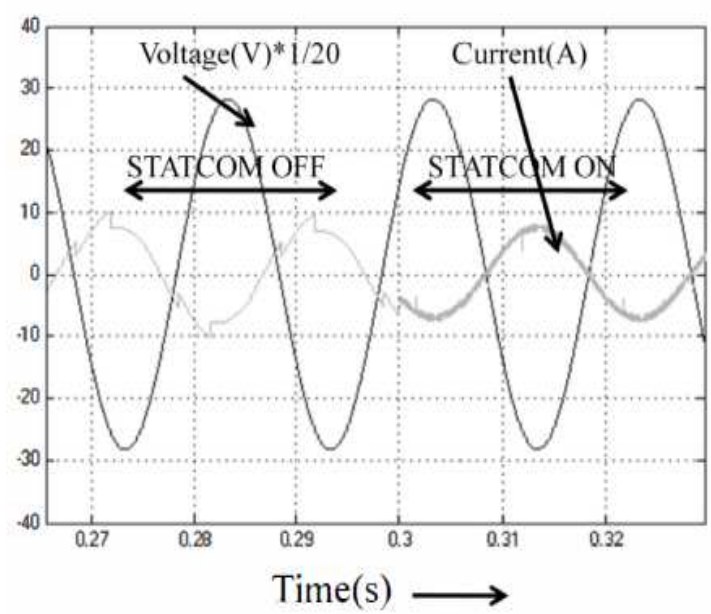

Fig 13. Instantaneous Value of grid Voltage and current for one phase

When STATCOM controller is made $\mathrm{ON}$, at $\mathrm{t}=\mathrm{O} .3 \mathrm{~s}$, it starts to mitigate the grid reactive power without any change in any other parameters. Instantaneous reactive power value of grid, load and induction generator is shown in fig 14, 15, and 16 respectively

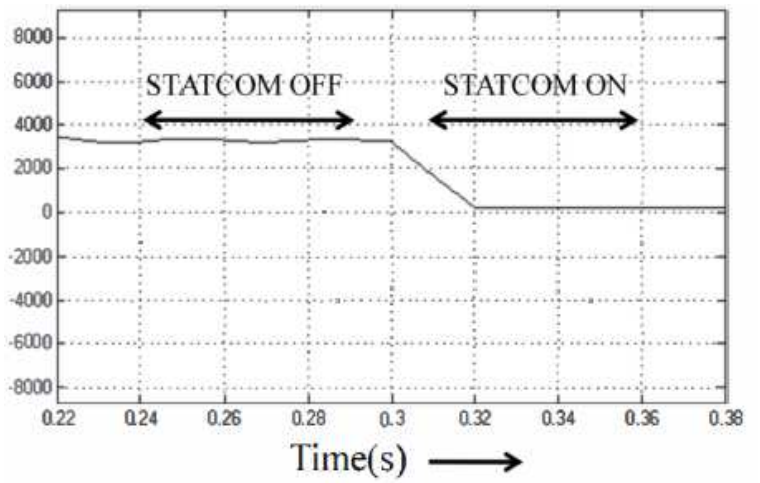

Fig 14 Instantaneous Value of Source reactive power

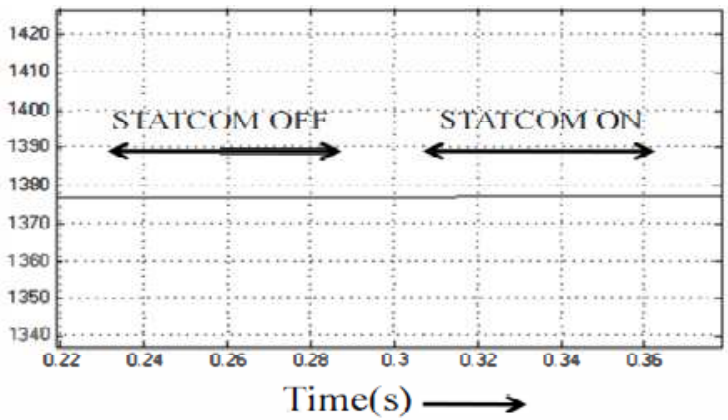

Fig 15. Instantaneous Value of Load reactive power. 


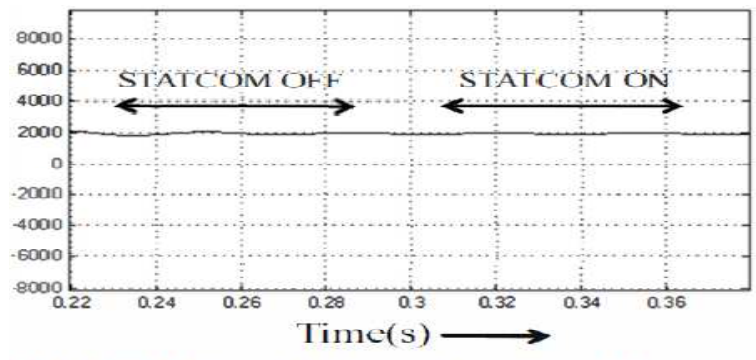

Fig 16 Instantaneous Value of reactive power requirements of Induction generator

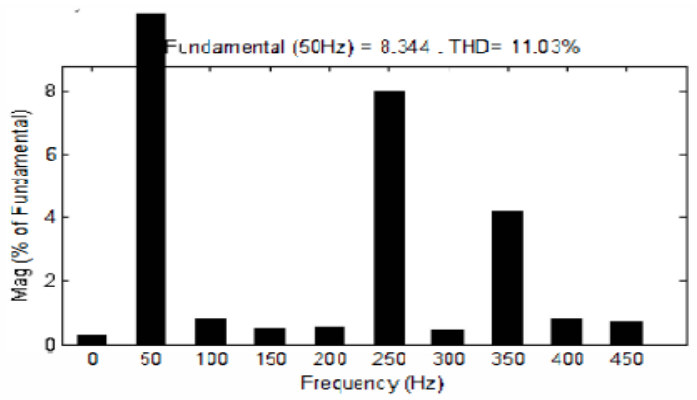

Fig 17.FFT analysis of source current before compensation

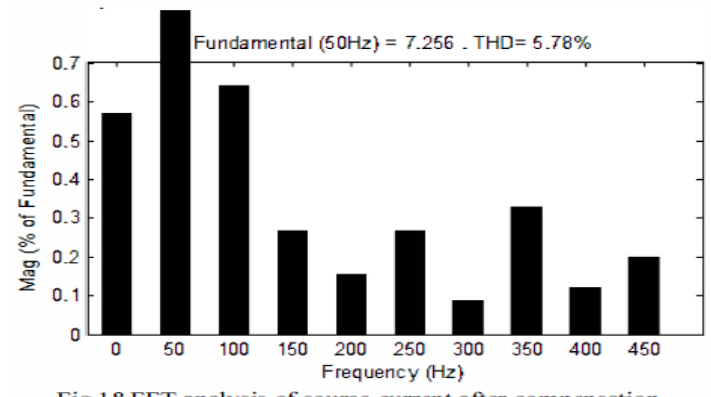

Fig 18.FFT analysis of source current after compensation

TABLE III

\begin{tabular}{|c|c|c|}
\hline Parameters & $\begin{array}{c}\text { Before } \\
\text { Compensation }\end{array}$ & $\begin{array}{c}\text { After } \\
\text { Compensation }\end{array}$ \\
\hline $\begin{array}{c}\text { Grid Reactive } \\
\text { power(VAR) }\end{array}$ & 3327 & 255 \\
\hline $\begin{array}{c}\text { Load Reactive } \\
\text { power(VAR) }\end{array}$ & 1377 & 1377 \\
\hline $\begin{array}{c}\text { Induction } \\
\text { generator } \\
\text { Reactive } \\
\text { power(VAR) }\end{array}$ & 1950 & 1950 \\
\hline \begin{tabular}{c} 
Grid power factor \\
\hline $\begin{array}{c}\text { Total harmonic } \\
\text { distortion (\%) }\end{array}$
\end{tabular} -0.8748 & -0.9978 \\
\hline
\end{tabular}

TABLE II

System parameters

\begin{tabular}{|c|c|c|}
\hline S.NO & Parameters & Rating \\
\hline 1 & Grid voltage & 3phase,415V,50HZ \\
\hline 2 & $\begin{array}{l}\text { Induction } \\
\text { generator }\end{array}$ & $4 \mathrm{KW}, 400 \mathrm{~V}, 50 \mathrm{~Hz}, 1430 \mathrm{rpm}$ \\
\hline 3 & $\begin{array}{l}\text { Linc scries } \\
\text { inductance }\end{array}$ & $0.1 \Omega, 0.022 \mathrm{H}$ \\
\hline 4 & $\begin{array}{l}\text { Inverter } \\
\text { parameters }\end{array}$ & $\begin{array}{l}\text { Dc link voltage }=900 \mathrm{~V} \\
\text { DC link capacitance } \\
=8794 \mu \mathrm{f} \\
\text { Switching frequency }= \\
10 \mathrm{KHz}\end{array}$ \\
\hline 5 & Load & Non linear load $=2 \mathrm{KW}$ \\
\hline
\end{tabular}

\section{CONCLUSIONS}

This paper presents the STATCOM-based control Scheme for reactive power compensation and harmonic reduction in grid connected wind generating system feeding non linear load. The control system for the STATCOM is simulated using MATLAB/SIMULINK. The Simulation results shows the grid voltage and current are in-phase, making the power factor unity, which implies that the reactive power demand of Induction generator and load is no longer, fed by the grid rather it is supplied by the STATCOM. Also the shape of the grid current is almost sinusoidal and the \%THD has been improved from $11.08 \%$ to $5.78 \%$ after compensation. The proposed control scheme has improved the power quality requirement of a low voltage grid connected wind driven IG system feeding a non-linear load.

\section{REFERENCES}

[1] .Q. Tande 'Applying Power Quality Characteristics of wind turbine for Assessing impact on Voltage Quality', Wind Energy, pp 52, 2002

[2] Z. Chen, E. Spooner, 'Grid Power Quality with Variable Speed Wind Turbines', IEEE Trans on Energy Conversion, Vol.16, No .2, pp 148- 154, June 200I.

[3] L. H. Hansen, L. Helle, F. Blaabjerg, E. Ritchie, S. MunkNielsen, H.Binder, P. SOrensen and B. Bak - Jensen "Conceptual Survey of Generators and Power Electronics for Wind Turbines ", Ris0 National Laboratory, Roskilde, Denmark, December 2001.

[4] A. Arulampalam, M. Bames \& NJenkins, Power quality and stability improvement of a wind farm using STATCOM, Proc. TEE Generation, Transmission \& Distribution, Vol. 153, No.6, 2006, 701-710.

[5] Z.Saad-Saoud, M.1.Lisboa, 1.B.Ekanayake, N. Jenkins \& G.Strbac, Application of STATCOMs to wind farms, Proc. TEE Generation, Transmission \& Distribution, Vo1.I45, No. 5, 1998, 511-516. 
[6] A. Arulampalam, 1.B.Ekanayake \& NJenkins, Application study of a STATCOM with energy storage, Proc. IEE Generation, Transmission \&Distribution, Vol. 150, No. 3, 2003, 373-384.

[7] Fang Zheng Peng, Jih-Sheng Lai, 'Generalized Instantaneous Reactive Power Theory for Three-phase Power Systems', IEEE on instrumentation and measurement, vol. 45, no. I, Feb, 1996

\section{BIOGRAPHIES:}

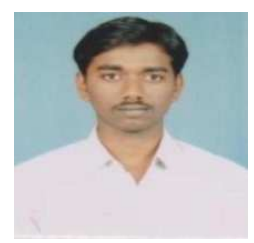

Sk. Baji babu student of PrakasamEngineering College is currently pursing M.Tech in Power Electronics specialization. He completed B.Tech (EEE) from JNTUK. His area of interests includes Facts, AC \& DC Drives.

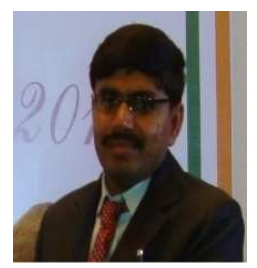

M.Bala Subba Reddy, HOD(EEE Dept.,) in Prakasam Engineering College Pursuing P.hd in JNTUK.He got M.Tech,POWER SYSTEMS from NIT, Trichy. He completed B.Tech (EEE) from Madras Uiversity. His areas of research interest includePower Electronics, Electrical machines and AC \& DC drives.

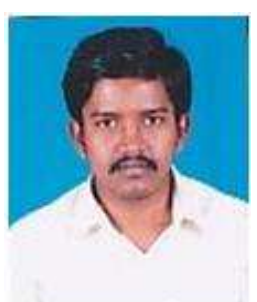

T. Madhu is Asst. Professor in EEE Dept., of Prakasam Engineering College, kandukur. He completed M.Tech, POWER ELECTRONICS from JNTUK. $\mathrm{He}$ completed B.Tech (EEE) from JNTUK.His area of interests includes in the subjects of Machine Modelling, Facts etc., 